\section{When is an Atypical DVA an AVM?}

We read with great interest a recent letter in the American Journal of Neuroradiology by Fushimi et al. ${ }^{1}$ They report a developmental venous anomaly (DVA) with unusual imaging findings on 3T susceptibility-weighted imaging, and they suggest that it may reflect a "relatively higher flow in the DVA...". We wish to suggest that increased flow in a DVA would be considered an atypical feature and may, in fact, reflect that this lesion represents a mixed vascular malformation with some imaging features of both a DVA and an arteriovenous malformation (AVM). Im et $\mathrm{al}^{2}$ reported in the June issue of the Journal of Neurosurgery 15 cases of "Venous Predominant Parenchymal Arteriovenous Malformations." The editorial in the same issue highlights the difficulty in identifying these unusual AVMs without angiography. It seems to us that this technique of susceptibilityweighted imaging at high field has the potential to differentiate a DVA from a venous predominant parenchymal arteriovenous malformation, but there is limited experience with this imaging technique in a clinical setting at this point. We believe it would be of considerable interest and importance to the patient reported by Fushimi et al $^{1}$ to perform angiography because treatment may be warranted if there is evidence of AV shunting.
We would like to draw attention to this entity that is not widely appreciated in the neuroradiology community and encourage investigations into noninvasive techniques that might differentiate these similar-appearing vascular lesions.

\section{References}

1. Fushimi $Y$, Miki Y, Togashi K, et al. A developmental venous anomaly presenting atypical findings on susceptibility-weighted imaging. AJNR Am J Neuroradiol 2008;29:E56.

2. Im SH, Han MH, Kwon BJ, et al. Venous-predominant parenchymal arteriovenous malformation: a rare subtype with venous drainage pattern mimicking developmental venous anomaly. J Neurosurg 2008;108:1142-47

A. Mamourian

Department of Radiology

Hospital of the University of Pennsylvania

Philadelphia, $\mathrm{Pa}$

R. Wallace

Division of Neuroradiology

Barrow Neurological Institute

Phoenix, Ariz 